\title{
Impact of the $\mathrm{CHA}_{2} \mathrm{DS}_{2}$-VASc Score on Anticoagulation Recommendations for Atrial Fibrillation
}

\author{
Pamela K. Mason, MD, Douglas E. Lake, PhD, John P. DiMarco, MD, PhD, John D. \\ Ferguson, MBChB, MD, J. Michael Mangrum, MD, Kenneth Bilchick, MD, Liza P. Moorman, \\ RN, ACNP-BC, and J. Randall Moorman, MD \\ University of Virginia Health System, Charlottesville
}

\begin{abstract}
BACKGROUND-The Congestive heart failure, Hypertension, Age $\geq 75$ years, Diabetes mellitus, Stroke $\left(\mathrm{CHADS}_{2}\right)$ score is used to predict the need for oral anticoagulation for stroke prophylaxis in patients with atrial fibrillation. The Congestive heart failure, Hypertension, Age $\geq$ 75 years, Diabetes mellitus, Stroke, Vascular disease, Age 65-74 years, Sex category $\left(\mathrm{CHA}_{2} \mathrm{DS}_{2^{-}}\right.$ VASc) schema has been proposed as an improvement. Our objective is to determine how adoption of the $\mathrm{CHA}_{2} \mathrm{DS}_{2}-\mathrm{VASc}$ score alters anticoagulation recommendations.
\end{abstract}

METHODS-Between 2004 and 2008, 1664 patients were seen at the University of Virginia Atrial Fibrillation Center. We calculated the $\mathrm{CHADS}_{2}$ and $\mathrm{CHA}_{2} \mathrm{DS}_{2}-\mathrm{VASc}$ scores for each patient. The 2006 American College of Cardiology/American Heart Association/Heart Rhythm Society guidelines for atrial fibrillation management were used to determine anticoagulation recommendations based on the $\mathrm{CHADS}_{2}$ score, and the 2010 European Society of Cardiology guidelines were used to determine anticoagulation recommendations based on the $\mathrm{CHA}_{2} \mathrm{DS}_{2^{-}}$ VASc score.

RESULTS-The average age was $62 \pm 13$ years, and $34 \%$ were women. Average $\mathrm{CHADS}_{2}$ and $\mathrm{CHA}_{2} \mathrm{DS}_{2}$-VASc scores were $1.1 \pm 1.1$ and $1.8 \pm 1.5$, respectively $(P<.0001)$. The $\mathrm{CHADS}_{2}$ score classified $33 \%$ as requiring oral anticoagulation. The $\mathrm{CHA}_{2} \mathrm{DS}_{2}-\mathrm{VASc}$ score classified $53 \%$ as requiring oral anticoagulation. For women, $31 \%$ had a $\mathrm{CHADS}_{2}$ score $\geq 2$, but $81 \%$ had a $\mathrm{CHA}_{2} \mathrm{DS}_{2}$-VASc score $22(P=.0001)$. Also, $32 \%$ of women with a $\mathrm{CHADS}_{2}$ score of zero had a $\mathrm{CHA}_{2} \mathrm{DS}_{2}$-VASc score $\geq 2$. For men, $25 \%$ had a $\mathrm{CHADS}_{2}$ score $\geq 2$, but $39 \%$ had a $\mathrm{CHA}_{2} \mathrm{DS}_{2}$ VASc score $\geq 2(P<.0001)$.

CONCLUSION-Compared with the $\mathrm{CHADS}_{2}$ score, the $\mathrm{CHA}_{2} \mathrm{DS}_{2}$-VASc score more clearly defines anticoagulation recommendations. Many patients, particularly older women, are redistributed from the low- to high-risk categories.

\section{Keywords}

Anticoagulation; Atrial Fibrillation; Stroke; Warfarin

Requests for reprints should be addressed to: Pamela K. Mason, MD, University of Virginia Health System, Box 800158, Charlottesville, VA 22908.Pkm5f@ virginia.edu.

Conflict of Interest: None.

Authorship: All authors had access to the data and played a role in writing this manuscript. 
Stroke is one of the most devastating complications of atrial fibrillation causing significant morbidity and mortality. ${ }^{1,2}$ Anticoagulant medications, particularly aspirin and warfarin, have been shown to decrease the risk of stroke in patients with atrial fibrillation. ${ }^{3,4}$ Warfarin is superior to aspirin for stroke prevention; however, it has an increased risk of bleeding. ${ }^{5,6}$ Recently, dabigatran has been released as a possible alternative to warfarin therapy for nonvalvular atrial fibrillation. Available data suggest that both the stroke prevention benefit and bleeding complications are similar to those of warfarin. ${ }^{7}$ Risk stratification is important to determine which patients have a stroke risk that is significant enough to justify the bleeding risk associated with these oral anticoagulants.

Multiple risk stratification schemes to predict stroke in patients with atrial fibrillation have been proposed over the last several decades. ${ }^{8}$ In 2001, Gage et $\mathrm{al}^{9}$ validated the Atrial Fibrillation Investigators score and the Stroke Prevention and Atrial Fibrillation score, as well as a new score, the Congestive heart failure, Hypertension, Age 275 years, Diabetes mellitus, Stroke $\left(\mathrm{CHADS}_{2}\right)$ (Table 1). ${ }^{9}$ The $\mathrm{CHADS}_{2}$ schema most accurately predicted the risk of stroke and has become the standard as described in the 2006 American College of Cardiology/American Heart Association/Heart Rhythm Society guidelines for the management of atrial fibrillation. ${ }^{10}$ Despite its common use, several concerns have remained. First, more recent studies do not show that the CHADS 2 score has good predictive value. An evaluation of the Anticoagulation and Risk Factors in Atrial Fibrillation Cohort demonstrated a poor correlation between $\mathrm{CHADS}_{2}$ score and thromboembolic events. ${ }^{11}$ Second, there are several known risk factors for stroke in atrial fibrillation, particularly very old age, female gender, and vascular disease, which are not accounted for in the $\mathrm{CHADS}_{2}$ score. ${ }^{12,13}$ The 2006 guidelines discuss these risk factors but do not specify how these should be used in risk stratification. ${ }^{10}$ Third, the risk of bleeding and the risk of stroke are similar for a $\mathrm{CHADS}_{2}$ score $=1$. Thus, aspirin is recommended for a score $=0$ and oral anticoagulation is recommended for a score of $\geq 2$, but either aspirin or oral anticoagulation is considered appropriate for intermediate-risk patients with a score $=1$. Cohorts have shown that $30 \%$ to $50 \%$ of atrial fibrillation patients have a $\mathrm{CHADS}_{2}$ score $=1$, implying that a large segment of atrial fibrillation patients have no clear recommendation for anticoagulation based on these criteria. ${ }^{9,14}$

\section{CLINICAL SIGNIFICANCE}

- The $\mathrm{CHADS}_{2}$ score is commonly used for stroke risk stratification for atrial fibrillation, but it does not have great predictive value.

- The $\mathrm{CHA}_{2} \mathrm{DS}_{2}-\mathrm{VASc}$ schema has been validated and seems to have improved value.

- Adoption of the $\mathrm{CHA}_{2} \mathrm{DS}_{2}$-VASc schema may as much as double the number of patients recommended for oral anticoagulation.

- This change will be seen mostly in older women.

A new schema, the Congestive heart failure, Hypertension, Age $\geq 75$ years, Diabetes mellitus, Stroke, Vascular disease, Age 65-74 years, Sex category $\left(\mathrm{CHA}_{2} \mathrm{DS}_{2}-\mathrm{VASc}\right)$ score 
or Birmingham Schema, has been proposed recently and seems to have better predictive value (Table 2). ${ }^{15}$ The score relies on "definitive risk factors" (age $\geq 75$ and prior stroke/ transient ischemic attack) and "combination risk factors" (congestive heart failure, hypertension, age 65-74 years, diabetes, vascular disease, and female gender). This score has been incorporated into the European Society of Cardiology (ESC) guidelines and is becoming used in the United States. ${ }^{16,17}$ The ESC guidelines recommend oral anticoagulation for a score $\geq 2$ and aspirin or oral anticoagulation for a score $=1$, with oral anticoagulation "preferred." In addition to providing more clarity with regard to anticoagulation recommendations for intermediaterisk patients, evaluation of this schema demonstrated that fewer patients fall into the intermediate risk group. ${ }^{15}$ The annual adjusted stroke rates for both of these scoring systems are shown in Table 3.

We analyzed the $\mathrm{CHADS}_{2}$ and $\mathrm{CHA}_{2} \mathrm{DS}_{2}$-VASc scores for our Atrial Fibrillation Center population. We hypothesized that shifting our patients from the $\mathrm{CHADS}_{2}$ to $\mathrm{CHA}_{2} \mathrm{DS}_{2-}$ VASc schema would significantly alter the number and distribution of patients recommended for oral anticoagulation. This has significant implications for both cost and bleeding complication risk.

\section{MATERIALS AND METHODS}

There were 1664 consecutive initial visits seen at the University of Virginia Atrial Fibrillation Center from October 2004 to April 2008 for nonvalvular atrial fibrillation. Thirtyseven percent of the patients were referred by primary care physicians, and $61 \%$ of patients were referred by cardiologists. Referrals from within the University of Virginia Health system account for $19 \%$ of patients, $40 \%$ come from our primary referral area, and $91 \%$ come from within the state of Virginia.

For each initial visit, a detailed database, designed according to American College of Cardiology/American Heart Association guidelines, was created using available medical records and patient history. ${ }^{18}$ The data collected included demographic information, date of initial diagnosis of atrial fibrillation, types of symptoms, dates of symptomatic recurrences, and all previous cardiac studies and therapies. Information regarding comorbidities also was collected, including prior stroke, diabetes, coronary artery disease, peripheral vascular disease, congestive heart failure, hypertension, and bleeding events. Major bleeding was defined as any event that required transfusion or hospitalization. Vascular disease was defined as coronary artery disease or peripheral vascular disease.

By using the Atrial Fibrillation Center initial visit database, the $\mathrm{CHADS}_{2}$ and $\mathrm{CHA}_{2} \mathrm{DS}_{2} \mathrm{VASc}$ scores were calculated retrospectively for each patient. The institutional review board of the University of Virginia approved this study.

\section{Statistical Analysis}

Continuous variables are expressed as mean \pm standard deviation, and the significance of differences was tested using the unpaired, 2-sided $t$ test. Categoric variables are expressed as numbers and percentages, and the $Z$ test was used to compare the corresponding proportions of men and women with these variables. Multivariable logistic regression analysis was 
performed. Covariates in the multivariable model included age and sex and significant univariate predictors $(P<.10) . P$ values $<.05$ were considered statistically significant.

\section{RESULTS}

Of the 1664 patients, $1094(66 \%)$ were men and $570(34 \%)$ were women. The mean ages for women at diagnosis and referral were $62.7 \pm 13.6$ and $68.0 \pm 11.9$ years, respectively, and the mean ages for men at diagnosis and referral were $57.3 \pm 14.0$ and $62.4 \pm 13.0$ years, respectively $(P<.0001$ for each). When controlling for the older age of the women with multivariable logistic regression analysis, there were no substantial differences between men and women. Women were more likely to have paroxysmal atrial fibrillation (68\% vs 58\%; $P$ $<.0001)$ and described more symptoms, particularly palpitations ( $80 \%$ vs $73 \% ; P=.008)$. Patient comorbidities are demonstrated in Table 4 . There were no differences between men and women in comorbidities, with the exception of coronary artery disease and heart failure. Women were less likely to have coronary artery disease (13\% vs $16 \% ; P<.0001)$ but slightly more likely to have heart failure $(11 \% \mathrm{vs} 9 \% ; P=.031)$. At the time of the initial visit, the majority of men and women were being treated with antithrombotic medications. Aspirin was used in $27 \%$ of women and $31 \%$ of men $(P=.014)$. Warfarin was used in 59\% of women and $58 \%$ of men $(P=.014)$. However, $20 \%$ of patients were taking neither aspirin nor oral anticoagulation. Major bleeding was seen in $1 \%$ of patients before being seen in the Atrial Fibrillation Center. Antiarrhythmic medications were being used in $34 \%$ of patients.

The average $\mathrm{CHADS}_{2}$ and $\mathrm{CHA}_{2} \mathrm{DS}_{2}$-VASc scores were $1.1 \pm 1.1$ and $1.8 \pm 1.5$, respectively $(P<.0001)$. The $\mathrm{CHADS}_{2}$ score classified $34 \%$ as low risk (score $\left.=0\right), 33 \%$ as intermediate risk (score $=1$ ), and $33 \%$ as high risk (score $\geq 2$ ). The $\mathrm{CHA}_{2} \mathrm{DS}_{2}-\mathrm{VASc}$ score classified $27 \%$ as low risk (score $=0$ ), $20 \%$ as intermediate risk (score $=1$ ) and $53 \%$ as high risk (score 22 ). The mean $\mathrm{CHADS}_{2}$ and $\mathrm{CHA}_{2} \mathrm{DS}_{2}$-VASc scores in women were $1.2 \pm 1.0$ and $2.7 \pm 1.3$, respectively $(P<.0001)$. The mean $\mathrm{CHADS}_{2}$ and $\mathrm{CHA}_{2} \mathrm{DS}_{2}$-VASc scores in men were $1.0 \pm 1.1$ and $1.4 \pm 1.4$, respectively $(P<.0001)$. The distribution of scores in both men and women is demonstrated in Figure 1.

Applying the recommendations for anticoagulation based on the $\mathrm{CHA}_{2} \mathrm{DS}_{2}-\mathrm{VASc}$ score and 2010 ESC guidelines rather than the $\mathrm{CHADS}_{2}$ score and 2006 American College of Cardiology/American Heart Association/Heart Rhythm Society guidelines dramatically alters the numbers and distribution of patients definitively recommended for oral anticoagulation therapy (Figure 2). For women, $31 \%$ had a $\mathrm{CHADS}_{2}$ score $\geq 2$ but $81 \%$ had a $\mathrm{CHA}_{2} \mathrm{DS}_{2}$-VASc score $\geq 2(P<.0001)$. In men, $25 \%$ had a $\mathrm{CHADS}_{2}$ score $\geq 2$ but $39 \%$ had a $\mathrm{CHA}_{2} \mathrm{DS}_{2}$-VASc score $\geq 2(P<.0001)$. Also, $32 \%$ of women with a $\mathrm{CHADS}_{2}$ score $=$ 0 had a $\mathrm{CHA}_{2} \mathrm{DS}_{2}$-VASc score $=2$. This change was driven almost entirely by a combination of female gender and age $\geq 75$ years. $\mathrm{A} \mathrm{CHADS}_{2}$ score $=0$ increased to a $\mathrm{CHA}_{2} \mathrm{DS}_{2}$-VASc score $=2$ in only 3 women, according to a combination of female gender and vascular disease. In this population, no men with a $\mathrm{CHADS}_{2}$ score $=0$ had a $\mathrm{CHA}_{2} \mathrm{DS}_{2^{-}}$ VASc score $=2$. All of the women who were in the intermediate-risk group with a $\mathrm{CHADS}_{2}$ score $=1$ had a $\mathrm{CHA}_{2} \mathrm{DS}_{2}$-VASc score $\geq 2$, and thus would be definitively recommended for oral anticoagulation therapy. In contrast, $62 \%$ of men with an intermediate $\mathrm{CHADS}_{2}$ score $=$ 1 continued to have an intermediate $\mathrm{CHA}_{2} \mathrm{DS}_{2}$-VASc score $=1$. 


\section{DISCUSSION}

There is a marked shift in anticoagulation recommendations for patients with atrial fibrillation when the $\mathrm{CHA}_{2} \mathrm{DS}_{2}$-VASc stroke risk stratification schema as outlined in the ESC 2010 guidelines is used compared with the $\mathrm{CHADS}_{2}$ score. The most obvious difference is the elimination of the large intermediate-risk group without clear recommendations for anticoagulation. In this study, this accounted for one third of patients. By applying the $\mathrm{CHA}_{2} \mathrm{DS}_{2}$-VASc schema, the number of intermediate risk patients with a score $=1$ decreased to $20 \%$. Further, the $\mathrm{CHA}_{2} \mathrm{DS}_{2}-\mathrm{VASc}$ schema provides clarity by recommending oral anticoagulation over aspirin for these intermediate-risk patients, although aspirin is considered an acceptable alternative. ${ }^{16}$

Because female gender is part of the $\mathrm{CHA}_{2} \mathrm{DS}_{2}-\mathrm{VASc}$ score, it is predictable that women would be more likely to shift to the high-risk group compared with men. However, the $\mathrm{CHA}_{2} \mathrm{DS}_{2}$-VASc schema also gives much greater weight to advancing age, and women with atrial fibrillation tend to be older than men with atrial fibrillation, as was the case in this study. ${ }^{13}$ This combines to make the gender difference dramatic for anticoagulation recommendations when shifting from the $\mathrm{CHADS}_{2}$ score to the $\mathrm{CHA}_{2} \mathrm{DS}_{2}-\mathrm{VASc}$ schema. All intermediate-risk women shifted to the high-risk group. However, approximately two thirds of men with an intermediate $\mathrm{CHADS}_{2}$ score $=1$ continued to have a $\mathrm{CHA}_{2} \mathrm{DS}_{2}$-VASc score $=1$. In addition, one third of low-risk women by $\mathrm{CHADS}_{2}$ score moved into the highrisk group with the $\mathrm{CHA}_{2} \mathrm{DS}_{2}-\mathrm{VASc}$ score, whereas all men with a $\mathrm{CHADS}_{2}$ score $=0$ continued to have a $\mathrm{CHA}_{2} \mathrm{DS}_{2}$-VASc score $\leq 1$. Thus, adoption of the $\mathrm{CHA}_{2} \mathrm{DS}_{2}-\mathrm{VASc}$ score among physicians who adhere to guidelines has the potential to dramatically increase the number of women receiving oral anticoagulation while making little change in the number of men receiving oral anticoagulation.

It is important to recognize that the $\mathrm{CHA}_{2} \mathrm{DS}_{2}$-VASc score represents an entirely new schema and not merely an improvement of the $\mathrm{CHADS}_{2}$ score. The annualized adjusted risk of stroke is different with each scoring system as demonstrated in Table 3. Although the $\mathrm{CHADS}_{2}$ score was developed to identify patients with atrial fibrillation at high risk for stroke, the goal of the $\mathrm{CHA}_{2} \mathrm{DS}_{2}$-VASc score is to identify the truly low-risk patients who do not require oral anticoagulation therapy. Thus, this study is only evaluating changes in anticoagulation recommendations and does not address the patients' actual risk of stroke. In addition, this study in no way addresses the bleeding risk associated with anticoagulant medications. This is a significant issue because older women can be at increased risk of bleeding.

It is not clear how adoption of the $\mathrm{CHA}_{2} \mathrm{DS}_{2}$-VASc score would change actual clinical practice. Multiple studies have demonstrated that physicians do not adhere well to the current anticoagulation guidelines, with many low-risk patients receiving oral anticoagulation and many high-risk patients receiving neither oral anticoagulation nor aspirin. ${ }^{19,20}$ There were signs of this in our own population. Approximately two thirds of both men and women were receiving oral anticoagulation, implying an aggressive use of oral anticoagulation because by $\mathrm{CHADS}_{2}$ score, only one third of patients were truly high risk. Further complicating matters is the recent release of dabigatran, which seems to have 
similar stroke prevention effect and bleeding risk to warfarin based on the Randomized Evaluation of Long-Term Anticoagulation Therapy (RE-LY) trial, but it is not yet widely used. $^{7}$

The major advantage of the $\mathrm{CHADS}_{2}$ score has been its simplicity. It is a straightforward algorithm consisting of a small number of variables. The disadvantages are that a significant number of patients are left without clear anticoagulation recommendations and its predictive value is not great. The $\mathrm{CHA}_{2} \mathrm{DS}_{2}$-VASc score retains this simplicity and clarifies recommendations for intermediate-risk patients as outlined in the 2010 ESC guidelines. Further, studies have shown improved predictive value.

This study is limited as a retrospective review. It also is a single-center study, and although our referral area is large, it is still geographically limited. As a tertiary population, the population characteristics are somewhat different from the known population with atrial fibrillation in the United States. However, in this study a large number of patients, particularly older women, were redistributed from the lowto high-risk categories.

\section{CONCLUSIONS}

Adoption of the $\mathrm{CHA}_{2} \mathrm{DS}_{2}$-VASc score anticoagulation recommendations has the potential to dramatically increase the number of patients recommended for oral anticoagulation therapy. The full impact of this risk stratification scheme on strokes, bleeding complications, and cost remains to be seen.

\section{Acknowledgments}

Funding: None.

\section{References}

1. Cabin HS, Clubb S, Hall C. Risk of systemic embolization of atrial fibrillation without mitral stenosis. Am J Cardiol. 1990; 65:1112-1116. [PubMed: 2330896]

2. Benjamin EJ, Wolf PA, D'Agostino RB, et al. Impact of atrial fibrillation on the risk of death: the Framingham Heart study. Circulation. 1998; 98:946-952. [PubMed: 9737513]

3. Stroke Prevention in Atrial Fibrillation Investigators. Stroke prevention in atrial fibrillation: final results. Circulation. 1991; 84:527-539. [PubMed: 1860198]

4. Ezekowitz MD, Bridgers SL, James KE, et al. Warfarin in the prevention of stroke associated with nonrheumatic atrial fibrillation. N Engl J Med. 1992; 327:1406-1412. [PubMed: 1406859]

5. Petersen P, Godtfredsen J, Boysen G, et al. Placebo-controlled, randomized trial of warfarin and aspirin for prevention of thromboembolic complications in chronic atrial fibrillation: the Copenhagen AFASAK Study. Lancet. 2003; 333:175-179.

6. Go AS, Hylek EM, Chang Y, et al. Anticoagulation therapy for stroke prevention in atrial fibrillation: how well do randomized trials translate into clinical practice? JAMA. 2003; 290:26852692. [PubMed: 14645310]

7. Connolly SJ, Ezekowitz MD, Yusuf S, et al. Dabigatran versus warfarin in patients with atrial fibrillation. N Engl J Med. 2009; 361:1139-1151. [PubMed: 19717844]

8. Stroke Risk in Atrial Fibrillation Working Group. Comparison of 12 risk stratification schemes to predict stroke in patients with nonvalvular atrial fibrillation. Stroke. 2008; 39:1901-1910. [PubMed: 18420954] 
9. Gage BF, Waterman AD, Shannon W, et al. Validation of clinical classification schemes for predicting stroke: results from the National Registry of Atrial Fibrillation. JAMA. 2001; 285:28642870. [PubMed: 11401607]

10. Fuster V, Rydén LE, Cannom DS, et al. ACC/AHA/ESC 2006 guidelines for the management of patients with atrial fibrillation-executive summary. Circulation. 2006; 114:700-752.

11. Fang MC, Go AS, Chang Y, et al. ATRIA Study Group. Comparison of risk stratification schemes to predict thromboembolism in people with nonvalvular atrial fibrillation. J Am Coll Cardiol. 2008; 51:816-817. [PubMed: 18294565]

12. Benjamin EJ, Levy D, Vaziri SM, et al. Independent risk factors for atrial fibrillation in a population-based cohort: the Framingham Heart study. JAMA. 1994; 271:840-844. [PubMed: 8114238]

13. Kerr CR, Humphries K. Gender-related difference in atrial fibrillation. J Am Coll Cardiol. 2005; 46:1307-1308. [PubMed: 16198848]

14. Nieuwlaat R, Capucci A, Lip GY, et al. Euro Heart Survey Investigators. Antithrombotic treatment in real-life atrial fibrillation patients: a report from the Euro Heart Survey on Atrial Fibrillation. Eur Heart J. 2006; 27:3018-3026. [PubMed: 16731536]

15. Lip GYH, Nieuwlaat R, Pisters R, et al. Refining clinical risk stratification for predicting stroke and thromboembolism in atrial fibrillation using a novel risk factor based approach: the Euro Heart survey on atrial fibrillation. Chest. 2010; 137:263-272. [PubMed: 19762550]

16. Camm AJ, Kirchhof P, Lip GYH, et al. Guidelines for the management of atrial fibrillation. Euro Heart J. 2010; 31:2369-2429.

17. Broukhim M, Halperin JL. Stroke prevention in the high-risk atrial fibrillation patient: medical management. Curr Cardiol Rep. 2011; 13:9-17. [PubMed: 20953740]

18. McNamara RL, Brass LM, Drozda AS Jr, et al. American College of Cardiology/American Heart Association Task Force on Clinical Data Standards (Writing Committee to Develop Data Standards on Atrial Fibrillation); American College of Cardiology; American Heart Association. ACC/AHA key data elements and definitions for measuring the clinical management and outcomes of patients with atrial fibrillation: a report of the American College of Cardiology/ American Heart Association Task Force on Clinical Data Standards (Writing Committee to Develop Data Standards on Atrial Fibrillation). Circulation. 2004; 109:3223-3243. [PubMed: 15226233]

19. Zimetbaum PJ, Thosani A, Yu HT, et al. Are atrial fibrillation patients receiving warfarin in accordance with stroke risk? Am J Med. 2010; 123:446-453. [PubMed: 20399322]

20. Glazer NL, Dublin S, Smith NL, et al. Newly detected atrial fibrillation and compliance with antithrombotic guidelines. Arch Intern Med. 2007; 167:246-252. [PubMed: 17296879] 

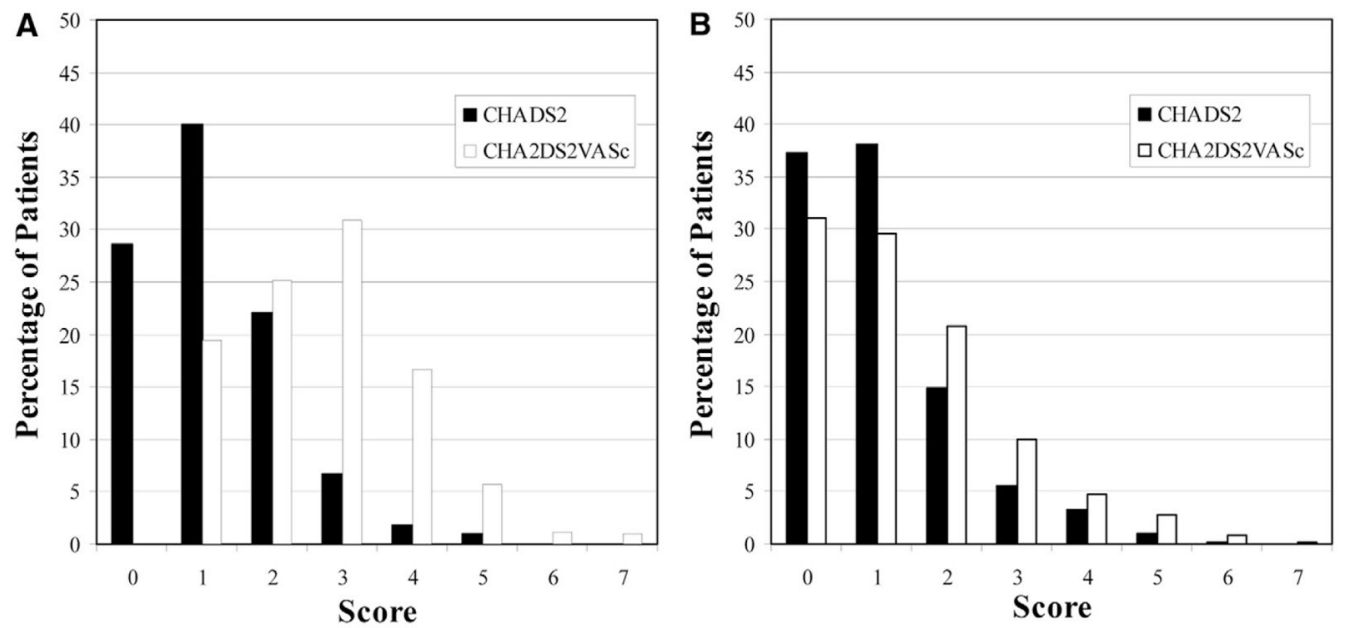

Figure 1.

Distribution of the $\mathrm{CHADS}_{2}$ and $\mathrm{CHA}_{2} \mathrm{DS}_{2}$-VASc scores among women (A) and men (B). 

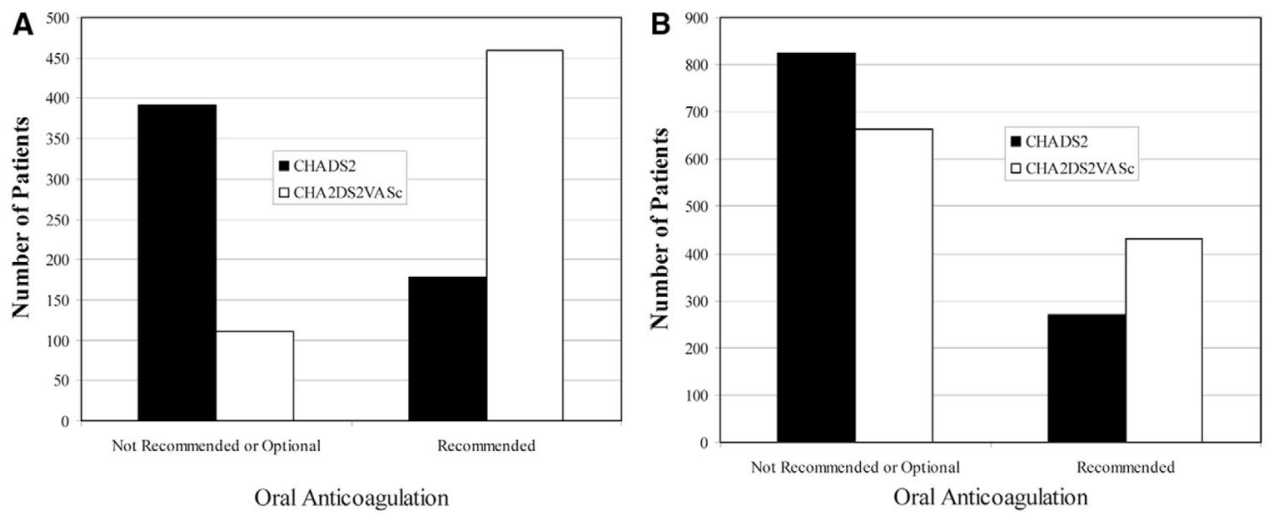

Figure 2.

Anticoagulation recommendations by $\mathrm{CHADS}_{2}$ and $\mathrm{CHA}_{2} \mathrm{DS}_{2}-\mathrm{VASc}$ scores in women (A) and men (B). 


\section{Table 1}

$\mathrm{CHADS}_{2}$ Score $^{9,10}$

\begin{tabular}{lll}
\hline $\mathrm{C}$ & Congestive Heart Failure & 1 point \\
$\mathrm{H}$ & Hypertension & 1 point \\
$\mathrm{A}$ & Age $\geq 75 \mathrm{y}$ & 1 point \\
$\mathrm{D}$ & Diabetes & 1 point \\
$\mathrm{S}_{2}$ & Stroke & 2 points \\
\hline
\end{tabular}

Maximum total score $=6$ points.

American College of Cardiology/American Heart Association/Heart Rhythm Society 2006 Anticoagulation Recommendations: Score $=0$ aspirin. Score $=1$ aspirin or oral anticoagulation. Score $\geq 2$ oral anticoagulation. 


\section{Table 2}

$\mathrm{CHA}_{2} \mathrm{DS}_{2}$-VASc Score ${ }^{15,16}$

\begin{tabular}{lll}
\hline C & Congestive Heart Failure & 1 point \\
$\mathrm{H}$ & Hypertension & 1 point \\
$\mathrm{A}_{2}$ & Age $275 \mathrm{y}$ & 2 points \\
$\mathrm{D}$ & Diabetes & 1 point \\
$\mathrm{S}_{2}$ & Stroke & 2 points \\
$\mathrm{V}$ & Vascular disease & 1 point \\
$\mathrm{A}$ & Age $265 \mathrm{y}$ & 1 point \\
$\mathrm{Sc}$ & Sex category, female & 1 point \\
\hline
\end{tabular}

Maximum total score $=9$ points.

ESC 2010 Anticoagulation Recommendations: Score $=0$ no therapy or aspirin (no therapy preferred). Score $=1$ aspirin or oral anticoagulation (oral anticoagulation preferred). Score $\geq 2$ oral anticoagulation. 
Table 3

Adjusted Risk of Stroke for $\mathrm{CHADS}_{2}$ and $\mathrm{CHA}_{2} \mathrm{DS}_{2}$-VASc Scores ${ }^{9,15}$

\begin{tabular}{lcc}
\hline Score & CHADS $_{\mathbf{2}}(\% / \mathbf{y})$ & $\mathbf{C H A}_{2} \mathbf{D S}_{\mathbf{2}}$-VASc $(\% / \mathbf{y})$ \\
\hline 0 & 1.9 & 0 \\
1 & 2.8 & 1.3 \\
2 & 4 & 2.2 \\
3 & 5.9 & 3.2 \\
4 & 8.5 & 4.0 \\
5 & 12.5 & 6.7 \\
6 & 18.2 & 9.8 \\
7 & & 9.6 \\
8 & & 6.7 \\
9 & & 15.2 \\
\hline
\end{tabular}

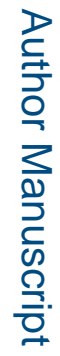

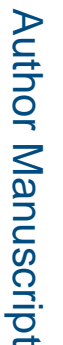

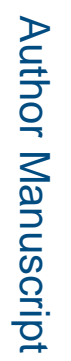

Am J Med. Author manuscript; available in PMC 2015 September 01. 
Table 4

Comorbidities

\begin{tabular}{|c|c|c|c|}
\hline & $\begin{array}{l}\text { All Patients (1664) } \\
\text { n (\%) }\end{array}$ & $\begin{array}{c}\text { Female (570) } \\
\text { n(\%) }\end{array}$ & $\begin{array}{l}\text { Male (1094) } \\
\text { n (\%) }\end{array}$ \\
\hline Heart failure* & $156(9)$ & $62(11)$ & $94(9)$ \\
\hline Hypertension & $931(56)$ & $334(59)$ & $597(55)$ \\
\hline Diabetes mellitus & $217(13)$ & $79(14)$ & $138(13)$ \\
\hline Stroke or transient ischemic attack & $114(7)$ & $35(6.1)$ & $79(7)$ \\
\hline Cardiovascular disease $^{* \dagger}$ & $258(16)$ & $77(14)$ & $181(17)$ \\
\hline
\end{tabular}

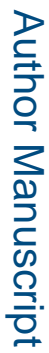

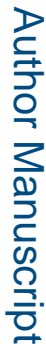

Comparisons were significant with a $P<.05$. 